\title{
Effect of Field Topographic Conditions on Plant Height of Rabi Sorghum in Vertisols
}

\author{
P. S. Kanannavar*, B. C. Punitha and U. K. Shanawad \\ Agricultural Engineer, IWMRC, Belavatagi, University of Agricultural Sciences, \\ Dharwad, India \\ *Corresponding author
}

Keywords

Land levelling, Grid survey,

Topographic condition, Rabi sorghum, Contours

Article Info

Accepted:

15 July 2020

Available Online:

10 August 2020

\begin{abstract}
A B S T R A C T
A field experiment was conducted in the research farms of Irrigation Water Management Research Center (IWMRC), Belvatagi, University of Agricultural Sciences (UAS) Dharwad during Rabi 2019 to study the effect of field topographic conditions on plant height of Rabi Sorghum in vertisols under rainfed situation. Grid survey $(10 \mathrm{~m} \mathrm{X10} \mathrm{m)} \mathrm{results} \mathrm{in} \mathrm{traditionally} \mathrm{levelled} \mathrm{field} \mathrm{indicated}$ that the average reduced level (RL) of field was $98.46 \mathrm{~m}$ with range of elevations $98.13 \mathrm{~m}$ to $98.80 \mathrm{~m}$ and standard deviation of grid elevations of $14.36 \mathrm{~cm}$. The standard deviation of grid elevations $(14.36 \mathrm{~cm})$ and 3-D contours indicated more undulations in topographic conditions. The average grid-wise plant height of Rabi sorghum was $1.59 \mathrm{~m}$ with range of grid - wise average plant heights varying from $1.34 \mathrm{~m}$ to $1.81 \mathrm{~m}$ with standard deviation of $9.8 \mathrm{~cm}$. It was found that variability of topographic conditions of the field resulted into variability in plant heights of Rabi sorghum. This calls for better land levelling methods to achieve more uniformity in the plant heights which would help in achieving uniform and higher crop yields.
\end{abstract}

\section{Introduction}

Environmental factors that affect plant growth include light, temperature, water, humidity, and nutrition. It is important to understand how these factors affect plant growth and development. In agriculture, with other parameters being same, land levelling plays a key role as undulating topography of the fields has a major impact on moisture conservation, water saving, the germination, plant heights and crop yields. Traditional methods of levelling lands are not only more cumbersome and time-consuming but also more expensive. In irrigated agriculture, the quality of land development or land levelling is having huge impact on soil moisture distribution, storage and variability in the field both spatially and temporally, crop growth, yields and irrigation efficiency. A significant (20-25\%) amount of irrigation water is lost during its application at the farm 
due to poor farm design and unevenness of the field (Cook and Peikert, 1960). Scientific land levelling saves irrigation water by facilitating field operations and increasing crop yields (Rickman, 2002). Dynamic levelling parameters such as standard deviation of elevations and levelling index determine the accuracy and quality of land levelling which affects soil moisture distribution and its variability and biometric growth of plants. For enhancing agricultural productivity the yield variability needs to be reduced. So, the present study during Rabi 2019 was conducted to assess effect of field topographic conditions on plant height of Rabi sorghum in vertisols under rainfed situation in the fields of Irrigation Water Management Research Center (IWMRC), Belvatagi, University of Agricultural Sciences (UAS) Dharwad, Karnataka. This calls for better land levelling methods / technology to achieve more precision and quality of land levelling to reduce spatial variability of plant heights and crop yields (Jat et al., 2004).

\section{Materials and Methods}

Grid survey: In the present study, grid survey $(10 \mathrm{~m} \mathrm{X} 10 \mathrm{~m})$ of topographic condition has been done. Grids were numbered 0 to 5 (X Axis i.e. from North-South direction) and with letters A to $\mathrm{L}$ (Y-Axis i.e. West-East direction). Each grid was labelled with its 4 corners e.g. AB12 indicating Rows A and B with 1 and 2 points. A field topographic survey with the help of auto level was carried out to find quality of traditional land levelling by knowing range of elevations as well as standard deviation of grid elevations.

Crop variety M-35-1 of Rabi sorghum was sown in the first week of November 2019 in block A3 of IWMRC Belavatagi. Irrigation Water Management Research Center Belvatagi, with latitude $15^{\circ} 34^{\prime} \mathrm{N}$ : longitude of $75^{\circ} 21^{\prime} \mathrm{E}$ and an altitude of $578 \mathrm{~m}$ above
MSL, falls under Northern dry Zone (Zone-3) of Karnataka. The particulars of selected field are presented in Table 1. The experiment was taken up in deep black soils under rainfed situation. The crop was harvested in the first week of April, 2020. No irrigation was given as sufficient soil moisture was observed as frequent rains (15 rainy days) were received for the crop. The total rainfall received was $293 \mathrm{~mm}, 91 \mathrm{~mm}$ and $6 \mathrm{~mm}$ in the months of October, November and December 2019, respectively. Also, grid-wise average plant height (4 plants in each grid before harvesting) data was collected to know variability of biometric observations. Contour maps with $5 \mathrm{~cm}$ contour interval for elevations and plant heights were plotted using the Golden Surfer software.

\section{Results and Discussion}

During the present study emphasis was on assessing the effect of field topographic conditions on plant height of Rabi sorghum in vertisols.

A. Spatial variability of topographic conditions of the field:

The topographic survey readings (reduced levels in $\mathrm{m}$ ) for all grid points are presented in Table 2. For a subjective assessment of accuracy of traditional land levelling and grid-wise yield variations, contour maps were plotted using the SURFER 8.0 package. The contour maps for grid elevations (3-D) were shown in Fig. 1. From contour maps it was observed that the land levelling was not so accurate as the undulations on the field were relatively more with closer contours. This was further confirmed with the results obtained from standard deviation of the surveyed readings. Results indicated that the average reduced level (RL) of entire field was $98.46 \mathrm{~m}$ with range of elevations $98.13 \mathrm{~m}$ to $98.80 \mathrm{~m}$ and standard deviation of grid elevations of 
$14.36 \mathrm{~cm}$. Higher standard deviation (14.36 $\mathrm{cm}$ ) of grid elevations (RLs) and contours (3D) indicated more spatial variability with topographic undulations. The same inferences were observed by Kanannavar et al., (2012). So, better land levelling methods / technology to achieve more precision and quality of levelling to reduce spatial variability of topographic conditions and crop growth and yields. This is in agreement with the findings of Agarwal and Goel (1981)

B. Spatial variability of average grid-wise plant heights of Rabi sorghum:

Table.1 Particulars of selected field

\begin{tabular}{|l|c|}
\hline \multicolumn{1}{|c|}{ Parameters } & Values \\
\hline Bulk density $\mathbf{g} / \mathbf{c c}$ & 1.40 \\
\hline Soil type & Deep black soil \\
\hline Length of field, $\mathbf{m}$ & 110 \\
\hline Width of field, $\mathbf{m}$ & 60 \\
\hline Area of field, $\mathbf{m}^{2}$ & 6600 \\
\hline Range of elevation of grid points, $\mathbf{c m}$ & -33 to 34 \\
\hline Maximum RL, $\mathbf{m}$ & 98.80 \\
\hline Minimum RL, $\mathbf{m}$ & 98.13 \\
\hline Standard deviation, cm & 14.36 \\
\hline
\end{tabular}

Table.2 Survey readings of grid points (RL, m) of the experimental plot

\begin{tabular}{|c|c|c|c|c|c|c|}
\hline $\begin{array}{c}\text { Grid point } \\
\begin{array}{c}\text { X-axis } \\
\text { Y-axis }\end{array}\end{array}$ & $\mathbf{0}$ & $\mathbf{1}$ & $\mathbf{2}$ & $\mathbf{3}$ & $\mathbf{4}$ & $\mathbf{5}$ \\
\hline $\mathbf{A}$ & $\mathbf{9 8 . 8 0}$ & 98.60 & 98.61 & 98.69 & 98.56 & 98.55 \\
\hline $\mathbf{B}$ & 98.59 & 98.54 & 98.60 & 98.58 & 98.52 & 98.56 \\
\hline $\mathbf{C}$ & 98.59 & 98.49 & 98.63 & 98.57 & 98.52 & 98.61 \\
\hline $\mathbf{D}$ & 98.60 & 98.54 & 98.61 & 98.60 & 98.48 & 98.64 \\
\hline $\mathbf{E}$ & 98.56 & 98.51 & 98.62 & 98.53 & 98.49 & 98.59 \\
\hline $\mathbf{F}$ & 98.51 & 98.45 & 98.52 & 98.50 & 98.45 & 98.54 \\
\hline $\mathbf{G}$ & 98.52 & 98.49 & 98.54 & 98.50 & 98.47 & 98.54 \\
\hline $\mathbf{H}$ & 98.49 & 98.42 & 98.5 & 98.45 & 98.40 & 98.48 \\
\hline $\mathbf{I}$ & 98.56 & 98.47 & 98.42 & 98.41 & 98.34 & 98.38 \\
\hline $\mathbf{J}$ & 98.25 & 98.34 & 98.36 & 98.29 & 98.28 & 98.14 \\
\hline K & 98.33 & 98.26 & 98.28 & 98.32 & 98.34 & 98.16 \\
\hline L & 98.32 & 98.20 & 98.21 & 98.23 & 98.17 & $\mathbf{9 8 . 1 3}$ \\
\hline $\begin{array}{c}\text { Overall } \\
\text { mean }\end{array}$ & & & & $\mathbf{9 8 . 4 6} \mathbf{m}$ & & \\
\hline
\end{tabular}


Table.3 Grid-wise plant heights of Rabi Sorghum (m) in the experimental plot

\begin{tabular}{|c|c|c|c|c|c|}
\hline \multirow{2}{*}{$\begin{array}{c}\text { Grid } \\
\text { No. }\end{array}$} & \multicolumn{5}{|c|}{ Average grid wise plant heights of $\mathbf{R a b i}$} \\
\cline { 2 - 6 } & $\mathbf{0 1}$ & $\mathbf{1 2}$ & $\mathbf{2 3}$ & $\mathbf{3 4}$ & $\mathbf{4 5}$ \\
\hline $\mathbf{A B}$ & 1.59 & 1.52 & 1.60 & 1.62 & 1.49 \\
\hline $\mathbf{B C}$ & 1.55 & 1.58 & 1.66 & 1.48 & 1.63 \\
\hline $\mathbf{C D}$ & 1.67 & 1.50 & 1.69 & 1.51 & 1.58 \\
\hline DE & 1.61 & 1.59 & 1.66 & 1.64 & 1.63 \\
\hline $\mathbf{E F}$ & 1.68 & 1.60 & 1.50 & 1.52 & 1.55 \\
\hline FG & 1.68 & 1.56 & 1.49 & 1.40 & 1.61 \\
\hline GH & 1.63 & 1.56 & 1.70 & 1.71 & 1.52 \\
\hline HI & 1.57 & 1.50 & 1.57 & 1.69 & 1.53 \\
\hline $\mathbf{I J}$ & 1.67 & 1.48 & 1.47 & 1.59 & 1.52 \\
\hline JK & 1.56 & 1.76 & 1.65 & 1.68 & 1.49 \\
\hline KL & 1.81 & 1.75 & 1.76 & 1.36 & 1.34 \\
\hline $\begin{array}{c}\text { Overall } \\
\text { mean }\end{array}$ & & & $\mathbf{1 . 5 9} \mathbf{m}$ & & \\
\hline
\end{tabular}

Fig.1 Three dimensional (3-D) contours for grid elevations of experimental plot
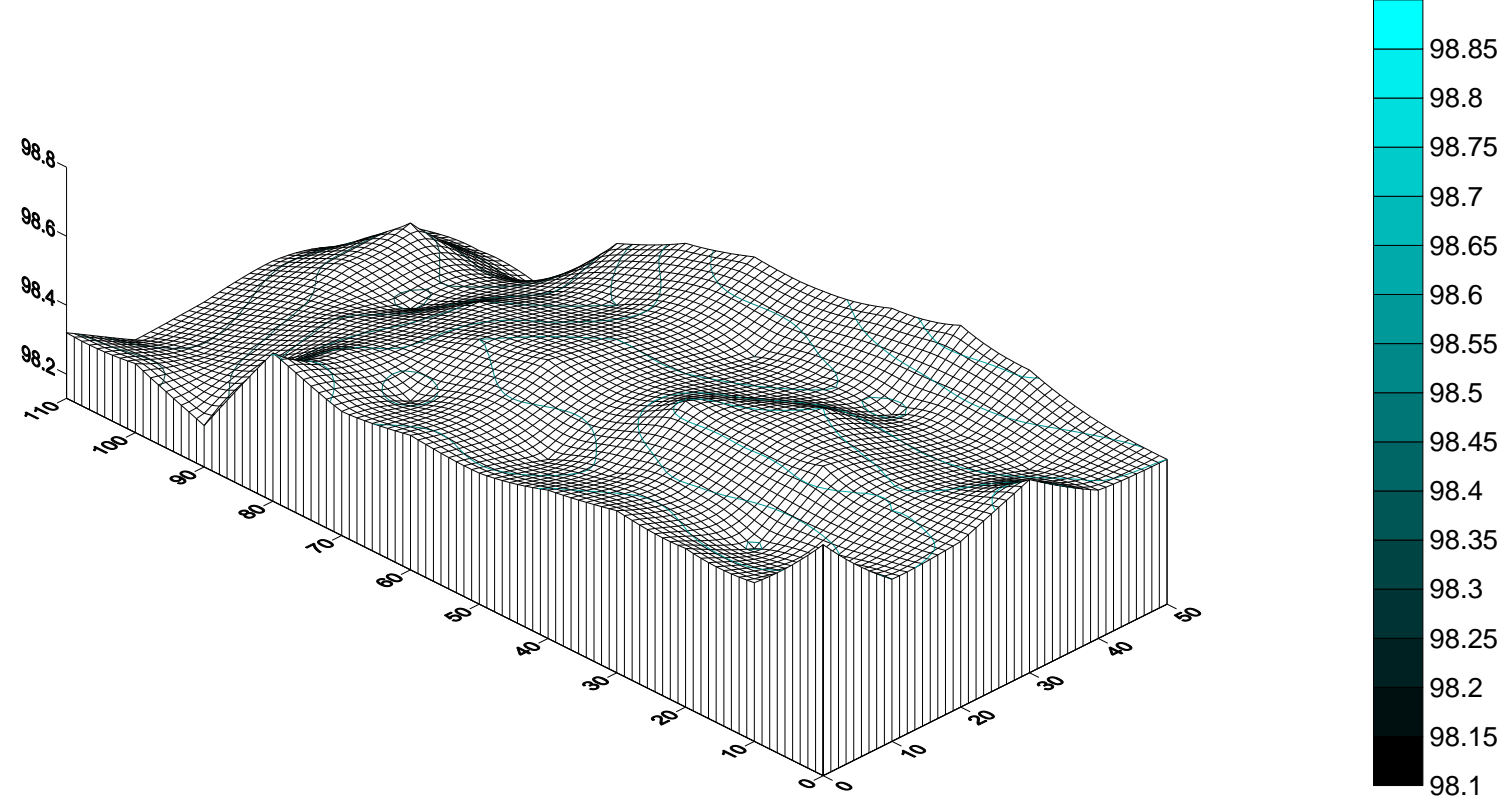
Fig.2 Two dimensional (2-D) contours for grid-wise plant height (m) of Rabi Sorghum

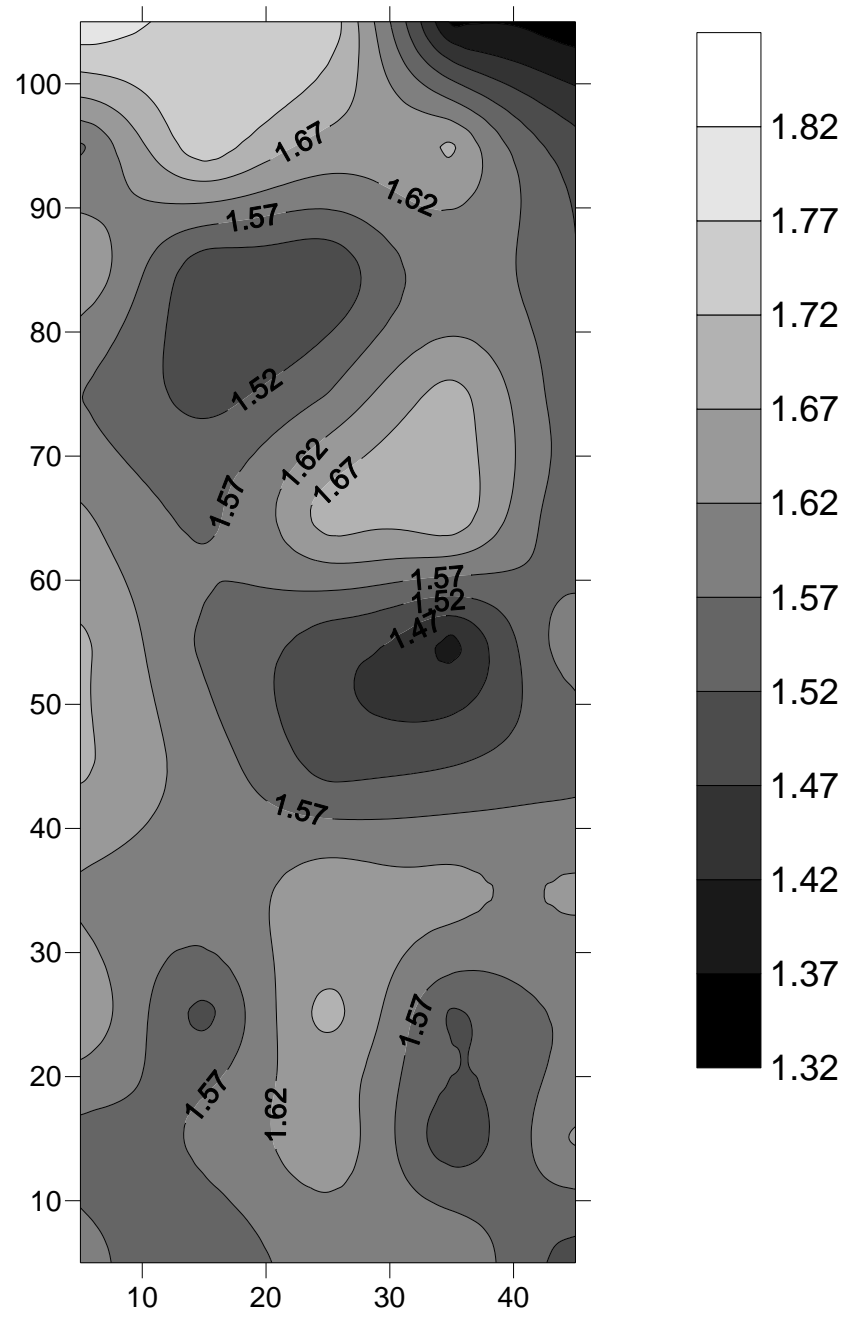

The results got from the study with respect to grid-wise plant heights of Rabi sorghum (m) in experimental plot are presented in Table 3. The contour maps for grid-wise plant height were shown in Fig. 2. The average grid-wise plant height of Rabi sorghum was $1.59 \mathrm{~m}$ with range of grid - wise average plant heights varying from $1.34 \mathrm{~m}$ to $1.81 \mathrm{~m}$ with standard deviation of $9.8 \mathrm{~cm}$. With all agronomic practices being same, it was found that variability of topographic conditions of the field resulted into variability in plant heights of Rabi sorghum. This was due to nonuniform soil moisture conservation due to undulations in the field as observed with higher spatial variability of topographic conditions (standard deviation of grid elevations as high as $14.36 \mathrm{~cm}$ ). Thus the effect of microtopography of the field affects soil moisture distribution, crop growth parameters and ultimately crop yields. The same inferences were corroborated by Ramos and Casasnovas (2006).

Conclusions are as follow:

Quality of land levelling is very important in rainfed agriculture to ensure uniform and higher soil and water conservation for uniform crop growth. 
It was observed from contour maps and from higher values of standard deviation of reduced levels that considerably lower accuracy in traditional land levelling as it depended on the skill of the driver.

Precise land development techniques are needed to address spatial variability of topographic conditions prevalent in agricultural fields and to achieve uniform crop growth.

\section{References}

Agarwal, M. C. and Goel, A. C., 1981. Effect of field levelling quality on irrigation efficiency and crop yield. Agricultural Water Management.4: 457-464

Cook, R. L. and F. W. Peikert, 1960. A comparison of tillage implement. The Journal of American Society of Agricultural Engineers. Vol. 31: 211214.

Jat, M. L. and Chandana, P., 2004, Precision land levelling- laser land levelling system. Rice- Wheat Information Sheet 48 (June): 3.

Kanannavar, P. S., Rajesh, N. L., Anuraja, B. Ravindra, Y. and Chilur, R. S., 2012, Temporal variability of levelling indices as influenced by different land levelling methods. Paper presented In: $3^{\text {rd }}$ Nation. Conf. on Agro-Informatics and Precision Agric., IIIT Hyderabad, pp. 330-331.

Ramos, M. C. and Martinez Casasnovas, J. A., 2006, Impact of land levelling on soil moisture and runoff variability in vineyards under different rainfall distributions in a Mediterranean climate and its influence on crop productivity, $J$. Hydr., 321:131-146.

Rickman, J. F., 2002. "Manual for laser land leveling". Rice-Wheat Consortium Technical Bulletin Series 5. New Delhi110 012, India: Rice-Wheat Consortium for the Indo-Gangetic plains, p. 24.

\section{How to cite this article:}

Kanannavar, P. S., B. C. Punitha and Shanawad, U. K. 2020. Effect of Field Topographic Conditions on Plant Height of Rabi Sorghum in Vertisols. Int.J.Curr.Microbiol.App.Sci. 9(08): 1349-1354. doi: https://doi.org/10.20546/ijcmas.2020.908.153 